FACULDAT DE CIENCIAS SOCIALES

DEPARTAMENTO DE EDUCAÇÃO

PÓS-GRADUAÇÃO STRICTO SENSU EM CIÊNCIAS DA EDUCAÇÃO

\title{
A INTERPRETAÇÃO DOS PROCESSOS HISTÓRICOS DA EDUCAÇÃO INCLUSIVA E OS CAMINHOS PARA SUA EFETIVAÇÃO NO PROCESSO DE ENSINO APRENDIZAGEM
}

ALEX BATISTA DE ANDRADE

ASSUNÇÃO - PARAGUAI 
FACULDAT DE CIENCIAS SOCIALES

DEPARTAMENTO DE EDUCAÇÃO

PÓS-GRADUAÇÃO STRICTO SENSU EM CIÊNCIAS DA EDUCAÇÃO

\section{A INTERPRETAÇÃO DOS PROCESSOS HISTÓRICOS DA EDUCAÇÃO INCLUSIVA E OS CAMINHOS PARA SUA EFETIVAÇÃO NO PROCESSO DE ENSINO APRENDIZAGEM}

ALEX BATISTA DE ANDRADE

Artigo apresentado ao Professora Dra . Martha como requisito formativo final, no Mestrado em Ciências da Educação.

ASSUNÇÃO - PARAGUAI 


\section{A INTERPRETAÇÃO DOS PROCESSOS HISTÓRICOS DA EDUCAÇÃO INCLUSIVA E OS CAMINHOS PARA SUA EFETIVAÇÃO NO PROCESSO DE ENSINO APRENDIZAGEM}

ALEX BATISTA DE ANDRADE

\section{RESUMO}

A história da educação inclusiva tem seu inicio nos anos de 1970, com lutas constantes de segmentos sociais e políticos, um dos objetivos deste artigo e demonstrar como isso se da dentro da educação infantil, passando por um breve relato do começo dessa busca pela valorização e dignidade humana.

A educação especial está presente na educação infantil em termos legais o que leva aos objetivos deste artigo, identificar a educação especial na educação infantil, mostrar como tem acontecido à educação especial nestas escolas, descrever os processos pedagógicos e a relação escola, criança que tem necessidade educacional especial e família. Para tal apresenta-se a educação especial na perspectiva da educação inclusiva, descrevendo as práticas observadas em uma escola de educação infantil. Como acontece a educação especial na escola de educação infantil é o problema proposto e responder a esta questão requer hipotetizar que a educação especial precisa ser efetivada nestas escolas. A observação de campo associada à revisão bibliográfica gerou os dados discutidos na consideração final. Os Marcos Político-Legais da Educação Especial na Perspectiva da Educação Inclusiva (2010), a Resolução 02 que institui Diretrizes Nacionais Para a Educação Especial na Educação Básica (2001), Sassaki (1997) e Silva (2010) contribuir com uma visão teórica e prática da educação especial na educação infantil e constitui-se no fundamento teórico deste trabalho.

Palavras-chave: Educação especial, necessidades educativas especiais, inclusão escolar, educação inclusiva.

\section{ABSTRACT}

The history of inclusive education has its beginning in the 1970s, with constant struggles of social and political segments, one of the objectives of this article and to demonstrate how this takes place within the infantile education, passing through a brief report of the beginning of this search for the valorization and human dignity. Special education is present in children's education in legal terms which leads to the objectives of this article, to identify special education in children's education, to show how special education has happened in these schools, to describe the pedagogical processes and the relation school, child in need Educational and family. For this, special education is presented in 
the perspective of inclusive education, describing the practices observed in a kindergarten school. As special education in the kindergarten is the problem proposed and answering this question requires hypothesizing that special education needs to be carried out in these schools. The field observation associated with the bibliographic review generated the data discussed in the final consideration. The Political-Legal Frameworks of Special Education in the Perspective of Inclusive Education (2010), Resolution 02 establishing National Guidelines for Special Education in Basic Education (2001), Sassaki (1997) and Silva (2010) contribute with a theoretical and Practice of special education in children's education and constitutes the theoretical basis of this work.

Keywords: Special education, special educational needs, school inclusion, inclusive education.

"Se ignorarmos as necessidades das crianças, aquilo que efetivamente as incentivam a agir, nunca seremos capazes de entender seus avanços evolutivos para outro, porque cada avanço está ligado a uma mudança de motivos, inclinações e incentivos"

VYGOTSKY (1988)

A inclusão de alunos com necessidades educacionais específicas na sociedade requer não apenas a aceitação da diversidade humana, mas implica em transformação significativa de atitudes e posturas sociais no sentido de cumprir as determinações legais da constituição de 1988 e das resoluções relativas à inclusão educacional. A escola é por excelência o espaço das diferenças e aquilo que se apresenta aos olhos da sociedade, aparece com enorme concentração no espaço educacional, em especial da educação básica (Sassaki, 1997). As diferenças "naturais" acompanham os seres humanos em sua jornada sócio-histórica por sermos heterogênios por natureza, mas a concentração das diferenças no ambiente escolar leva a perceber que existem crianças que apresentam dificuldade na aprendizagem, deficiências, transtornos invasivos do desenvolvimento, síndromes e altas habilidades/superdotação ou por causas diversas que lhes conferem o título de diferentes.

Ao fazermos uma reflexão sobre o processo histórico sobre a construção de uma Unidade Educacional no campo da educação infantil é de suma importância voltar-se o 
olhar para quais espaços, sua temporalidade, profissionais que serão envolvidos, as metodologias e os recursos pedagógicos entre outros aspectos, que se direcionará para a formação social, cognitiva, tendo como princípio a permanência e acesso do educando no seu processo formativo e seu desenvolvimento intelectual e humano com respeito e acolhimento de suas deficiências, potencialidades e particularidades que são condicionadas em áreas especificas, no que se refere as que apresentam necessidades educacionais que são específicas, ou seja, que estão circunscritas a determinada característica do quadro clínico apresentado pela criança.

Este tipo de atenção especial direcionadas pelas Unidades de Ensino às crianças com dificuldades mais acentuadas de aprendizagem em seu sentido mais amplo, não somente a conteúdos pedagógicos, chama-se educação especial e perpassa a todos os níveis de educação, desde a educação básica até a educação superior. A educação especial, portanto, está presente sistema de ensino está em conformidade com prerrogativa da normativa legal apresentada na Resolução № 02 de 11 de Setembro de 2001, que estabelece diretrizes nacionais para a educação especial na educação básica (Brasil, 2001).

A educação especial nas escolas de educação básica se ocupa em atender as crianças que possuem deficiência, transtorno global do desenvolvimento, altas habilidades/ superdotação ou mesmo dificuldade na aprendizagem por outra causa a ser desvendada durante o processo de acompanhamento desta criança. (Brasil, 2001).

Neste sentido a educação infantil é a porta de entrada da criança no sistema regular de ensino, ela se constitui em um direito assegurado às crianças brasileiras de acordo com que está estabelecido na Constituição Federal Brasileira de 1988 (CF 88) que as garantias de acesso, permanência e qualidade para a formação das futuras gerações em um princípio de igualdade e democracia.

Art. $2^{\circ}$ A educação, dever da família e do Estado, inspirada nos princípios de liberdade e nos ideais de solidariedade humana, tem por finalidade o pleno desenvolvimento do educando, seu preparo para o exercício da cidadania e sua qualificação para o trabalho. (Brasil, 1996).

A Lei de Diretrizes e Bases da Educação Nacional confirma o dever do estado de oferecer educação em todas as modalidades de forma gratuita, assegurando acesso e permanência a todas as crianças. Para a Unidade Escolar a criança leva sua ansiedade pela descoberta, pelo conhecimento do novo, do diferente, sua necessidade de tocar, sentir, ouvir, falar, dançar, suas duvidas e curiosidades. Por isso a importância de estar sempre reformulando a prática pedagógica considerando os aspectos sociais, cognitivos, 
afetivos e culturais de cada um e principalmente identificando a necessidade educacional específica.

Assim apresentam-se os objetivos deste artigo, é identificar o processo da educação especial na escola pública de educação da educação básica que permeia desde a pré - escola até o ensino médio, procurando com isso fazer uma análise sobre o processo de inserção da educação especial nesta etapa do ensino aprendizagem, descrever os processos pedagógicos realizados pela educação especial com as crianças ,adolescentes e jovens e sua relação escola, pois os alunos devem ser atendidos e aguçados em todos as suas possibilidades e potencialidades do conhecimento com o apoio do toda equipe escolar e sobretudo de suas famílias.

Portanto, não podemos encarar educação inclusiva e o ensino especial apenas como forma de atender as leis educacionais vigentes, mas sim como uma oportunidade de garantir a socialização de estudantes com professores, outros alunos com suas realidades culturais e histórias diversificadas não parecem estar sendo executados com clareza nestas escolas na sua formação humana, social, emocional e intelectual. É certo que em muitos espaços de ensino esse modalidade de ensino não acontece de forma plena, mas em outros é maravilhoso ver a atuação de todo o corpo docente da escola e m conjunto com a família estimular a aprendizagem destes alunos com práticas exitosas e recursos pedagógicos que mudam a realidade dos alunos nos vários aspectos cognitivos e sócio- culturais.

$\mathrm{Na}$ tentativa de procurar respostas sobre a educação inclusiva e seu papel social, colocamos à prova a hipótese de ela é parte fundamental do processo educacional nas escolas de educação infantil, mas que não tem sido efetivada como determina as diretrizes de bases do Ministério da Educação, por parte da União, Estados e Munícipios no que se refere a infraestruturas, recursos didáticos especializados e a formação continua de professores. Acreditamos que a educação inclusiva não pode ficar apenas no papel, ser citada como algo que existe apenas na formalidade. Ela precisa acontecer de fato, com todas as suas atuações práticas para contribuir com o processo de inclusão educacional das crianças que apresentam necessidades educacionais específicas.

O documento do Ministério da Educação (MEC) Política Nacional de Educação Especial na Perspectiva da Educação Inclusiva, foi utilizado como fonte de dados para discutir a educação especial na escola de educação infantil. A revisão bibliográfica conta também com uma visão sobre o processo de inclusão e sua configuração em 
escolas públicas de educação infantil, tendo a educação especial como modalidade específica da educação inclusiva.

\section{Aspectos Históricos da Educação Inclusiva no contexto Educacional}

Fazendo um recorte histórico da educação inclusiva o que se observa que no Império Brasileiro já existia atendimento a pessoas com problemas físicos e mentais com a criação de centros de atendimento especializados tais como: Imperial Instituto dos Meninos Cegos, em 1854, atual Instituto Benjamin Constant - IBC, e o Instituto dos Surdos Mudos, em 1857, hoje denominado Instituto Nacional da Educação dos Surdos INES, ambos no Rio de Janeiro. (Portal da Educação)

No início do século XX é fundado o Instituto Pestalozzi (1926), instituição especializada no atendimento às pessoas com deficiência mental; em 1954, é fundada a primeira Associação de Pais e Amigos dos Excepcionais - APAE; e, em 1945, é criado o primeiro atendimento educacional especializado às pessoas com superdotação na Sociedade Pestalozzi, por Helena Antipoff. (Ministério da Educação). Porém, a Educação Inclusiva foi datada pelo Ministério da Educação (MEC) nos anos de 1970, tendo sua busca no atendimento globalizado entre os seres sem discriminação de diferenças físicas, intelectuais e sociais, de certa forma aceita por algumas unidades escolares, que mesmo sem espaços e ambientes adequados se disponibilizaram a receber a diversidade humana.

\section{Princípios Legais da Educação Especial nas Escolas de Educação Infantil}

A educação infantil é parte integrante do processo da inclusão escolar que vem acontecendo no Brasil desde o final da década de 80, com a promulgação da Constituição Federal e com a nova Lei de Diretrizes e Bases da Educação Nacional.

Art. $2^{\circ}$ Os sistemas de ensino devem matricular todos os alunos, cabendo às escolas organizar-se para o atendimento aos educandos com necessidades educacionais especiais, assegurando as condições necessárias para uma educação de qualidade para todos (BRASIL, 2001).

A obrigação do estado de oferecer educação pública, gratuita e de qualidade, se estende para todos, incluindo para as crianças abaixo da idade escolar de seis anos. Estas escolas passam a ser chamadas de escolas de educação infantil e o processo 
contínuo de inclusão educacional está presente nestas escolas, tanto como cumprimento do princípio legal quanto com a promoção de uma educação voltada para abranger as dificuldades encontradas pela criança que apresenta deficiência ou transtorno global do desenvolvimento.

A educação especial é constituída de uma área de conhecimento e uma modalidade de ensino que tem como objetivo o desenvolvimento de práticas e estratégias pedagógicas voltadas para o aluno com necessidade educacional especial (SILVA, 2010. p. 09).

Este processo é possibilitado por meio da implantação da política nacional de educação especial na perspectiva da educação inclusiva, documento do Ministério da Educação que apresenta normativas para o atendimento pedagógico específico para as crianças que têm alguma deficiência, transtorno global do desenvolvimento ou altas habilidades/superdotação.

As diretrizes curriculares nacionais de todas as etapas e modalidades da Educação Básica estendem-se para a educação especial, assim como estas Diretrizes Nacionais para a Educação Especial estendem-se para todas as etapas e modalidades da Educação Básica (BRASIL, 2010. p. 09).

A educação infantil está inserida nas etapas da educação básica e, portanto a educação especial se inicia desde a entrada das crianças nestas escolas, como especifica a Resolução 02 de Setembro de 2001,

Art. 1ํ A presente Resolução institui as Diretrizes Nacionais para a educação de alunos que apresentem necessidades educacionais especiais, na Educação Básica, em todas as suas etapas e modalidades.

Parágrafo único. $O$ atendimento escolar desses alunos terá início na educação infantil, nas creches e pré-escolas, assegurando-lhes os serviços de educação especial sempre que se evidencie, mediante avaliação e interação com a família e a comunidade, a necessidade de atendimento educacional especializado. (BRASIL, 2001. p. 01).

Com a inclusão de crianças com deficiência ou transtorno global do desenvolvimento nas escolas de educação infantil, tem início o desenvolvimento da educação especial com estas crianças. A presença de uma sala de atendimento educacional especializado (AEE) facilitaria na promoção desta natureza de ensino, porém esta não é uma realidade nas escolas públicas brasileiras, mas a criança pode ser encaminhada para ser atendida em outra escola que possua sala de AEE e também ser acompanhada por uma equipe multiprofissional da mesma rede de ensino. $\mathrm{Na}$ escola, o aluno pode contar, de acordo com sua necessidade, com um professor de 
apoio à inclusão, que será o responsável, juntamente com o professor regente, coordenação pedagógica e equipe multiprofissional, por elaborar um plano de desenvolvimento individualizado e flexibilização de conteúdos para que a criança aprenda e desenvolva suas capacidades e habilidades.

O plano de desenvolvimento individualizado deve abordar dois aspectos, as informações e avaliação das condições gerais da criança na escola e na família em seus aspectos, clínico, social, cognitivo, afetivo e psicomotor e o plano pedagógico individualizado que visa trabalhar de modo a desenvolver todos os aspectos apontados como importantes na avaliação anterior, nunca deixando de considerar o cuidado e o brincar como essenciais e indissociados da aprendizagem da criança. (POKER. 2013). Deste modo ela poderá desenvolver seus cuidados de vida diária, sua autonomia, a socialização e o prazer por meio do lúdico e a aprendizagem de processos cognitivos superiores que ajudarão na construção da linguagem escrita e falada, da leitura e das noções matemáticas (VYGOTSKY. 1996).

\section{Educação Especial em uma Escola Pública de Educação Infantil}

Para iniciar a descrição dos dados encontrados durante a observação na escola de educação infantil, é preciso primeiro esclarecer que o questionamento acerca do fazer da educação especial dentro de um Centro de Educação Infantil (CMEI), surgiu quando cumpria o estágio curricular obrigatório na educação infantil. No qual pude presenciar a situação criança autista, surda, deficiente físico e mental nesta instituição, nos perguntamos como eram trabalhadas em suas especificidades e assim surgiu o desejo de observarmos mais a fundo a modalidade de educação especial na educação infantil.

Após o contato inicial com a gestão do Centro Municipal de Educação Infantil (CMEI) onde busquei s dados, foram realizadas visitas, uma para colher dados técnicos em conversas direcionadas à educação especial com a gestora e a coordenadora pedagógica e outra para acompanhar salas onde houvesse crianças que tinham professoras de apoio, podendo assim conversar com estas e com as professoras regentes. Não foi feito um questionário formal para ser aplicado, após análise e leitura de referenciais teóricos foram surgindo vários questionamentos, sobre as várias faces do ensino especial, pois escolas não podem ser apenas depósitos de crianças com 
necessidades especiais, mas é de suma importância que busquem soluções para cada situação. Nesta Unidade foi que são atendidas cento e cinquenta e três crianças em tempo integral, entrando para a instituição com a idade de três meses e cursando até o jardim III (Seis anos incompletos). As salas são divididas da seguinte forma, uns berçários, maternal um e dois, jardim um, com cerca de quinze alunos em cada sala. Uma sala de Jardim dois com mais ou menos 20 alunos em cada sala. Esta variação se explica pelo fato de uma necessidade de realizar senso para descobrir vagas ociosas deixadas por crianças desistentes.

As salas de berçário, maternal e jardim um contam com três professoras no período matutino e duas no período vespertino (muitas delas são estagiárias). O jardim dois conta com uma professora regente e uma professora de apoio (quando solicitado pela presença de aluno com necessidades especiais) no período matutino e a tarde segue com o mesmo sistema curricular. Ao todo são trinta e duas professoras entre regentes, e professoras de apoio (que são cinco), são doze os profissionais técnicos de apoio de higiene e alimentação, uma secretária, uma coordenadora pedagógica e uma gestora, totalizando cinquenta profissionais diariamente no Centro Municipal de Educação Infantil (CMEI), ainda que muitos trabalhem em apenas um turno.

O espaço físico precisa ser completamente adaptado e com acessibilidade, todas as oito salas de aula são climatizadas e têm seu próprio banheiro, trocadouro, bancada, armários, televisão com vídeos e brinquedos. Existe ainda uma brinquedoteca e um laboratório de computação que está sendo equipado, um campo gramado, uma área de lazer equipada com casa de bolinhas, percursos pedagógicos, cavalinhos de roda, carrinhos, bonecas, bolas e muitos brinquedos para a área sensorial e motora. $\mathrm{O}$ refeitório é amplo e apenas o berçário e maternal tomam alimentação separados. Tratase de uma escola extremamente bem equipada (para os moldes públicos) e adequada para a educação infantil.

A escola apresenta alguns casos de crianças com deficiência e transtorno global do desenvolvimento, sendo um autista, dois deficientes mentais, uma surda e uma deficiente físico. Cada uma destas crianças tem um professor de apoio à inclusão, que se encarrega de aplicar a flexibilização de conteúdo, acompanhar no pátio, facilitando o processo de socialização e adaptação, promovendo juntamente com a equipe multiprofissional e professora regente o plano de desenvolvimento individual.

O processo de educação especial a ser desenvolvido nos centros educacionais de educação infantil precisa garantir que a criança receba uma educação que envolve o 
contato com as demais crianças, o ensino de autocuidado, auto preservação e atividades de vida diária de maneira associada ao brincar e ao cuidado que as auxiliares da educação infantil promovem nos momentos de banho, de jogos e brincadeiras, de alimentação e também em sala com atividades diversificadas como culinária, danças, coreografias, ritmos, recitais, recortes, colagens, traçados, formas e pequenas escritas.

Com relação às ações em conformidade com outras secretarias, a gestora informou que existem parcerias com a assistência social e com a secretaria de saúde, garantindo acesso aos benefícios sociais, como bolsa escola, transporte escolar, tratamento médico na área de pediatria e psiquiatria, fonoaudiologia, psicologia e psicopedagogia, que atende não só as crianças deficientes, mas demais casos de problemas na aprendizagem ou atraso no desenvolvimento neuropsicomotor. Estas ações são promovidas pela Mediação da Inclusão da Secretaria municipal de educação e respaldadas pela Resolução 2 de 11 de setembro de 2001 no artigo 10:

Art. 10. Os alunos que apresentem necessidades educacionais especiais e requeiram atenção individualizada nas atividades da vida autônoma e social, recursos, ajudas e apoios intensos e contínuos, bem como adaptações curriculares tão significativas que a escola comum não consiga prover, podem ser atendidos, em caráter extraordinário, em escolas especiais, públicas ou privadas, atendimento esse complementado, sempre que necessário e de maneira articulada, por serviços das áreas de Saúde, Trabalho e Assistência Social (BRASIL, 2001).

Fica claro que quando se pretende desenvolver um trabalho de educação especial, ainda que seja na escola de educação infantil, isto é possível, mas é necessário que haja compromisso por parte da instituição para prever e prover os recursos físicos e humanos necessários ao desenvolvimento das atividades, bem como compromisso por parte da gestão, no sentido de estar aberta ao diálogo da inclusão, às novas concepções de educação especial na perspectiva da educação inclusiva, ao rompimento com paradigmas preconceituosos e segregacionistas e buscar construir parcerias tanto de demais instituições quanto com os pais, servidores e com toda a comunidade escolar, para criar uma apropriação do sentido da inclusão e do conhecimento necessário para construir uma educação inclusiva que dê resultados reais para as crianças e suas famílias.

\section{A Relação da Família da Criança Deficiente com a Escola Inclusiva}


A família é parte fundamental para o bom desenvolvimento da criança em uma escola de educação infantil onde se desenvolve a educação especial. É a família que trás as informações que auxiliarão na promoção das atividades adequadas à especificidade da deficiência de cada criança. O histórico clínico, social e físico da criança é extremamente importante para que a equipe de educação especial construa o plano de desenvolvimento individual da criança. Estas informações permitirão a compreensão da natureza da deficiência ou síndrome, os aspectos relacionados com a dificuldade que a criança enfrenta para aprender e se desenvolver e promover a flexibilização de conteúdo necessária para atender ao princípio legal e a necessidade educacional específica da criança.

\begin{abstract}
Histórica e culturalmente, estamos habituados [...] que se leia com os olhos, se fale com a boca, que se escreva com as mãos, que um determinado conceito seja elaborado em uma determinada fase da criança. Entretanto, sabemos que tais tarefas podem ser realizadas com ferramentas diferentes destas dispostas para a maioria das pessoas, assim como em tempos diferenciados. Podemos ler com os dedos, podemos falar com as mãos, podemos escrever com os pés e elaborar um conceito em diferentes momentos da nossa vida. (BRAUN, 2013, p. $61)$.
\end{abstract}

Através do autor Braun (2013), vemos que a criança que tem necessidade educacional específica, no contexto atual, de inclusão e incentivo à diversidade, tem direito a todo um processo adaptativo diferenciado, relacionado com as suas especificidades, ou seja, crianças que apresentam má formação congênita e que por este motivo têm os membros superiores atrofiados, ou inexistentes, podem sim escrever com os pés, ou com a boca, ou mesmo digitar com o cotovelo. Esta adaptação precisa ser muito bem trabalhada com a família, pois se ela continuar entendendo que só se escreve com a mão, nunca aceitará o desenvolvimento diferenciado por parte da criança. É extremamente importante trabalhar com a família toda a adaptação que necessita ser desenvolvida com a criança, independentemente de sua deficiência, assim o lar se tornará uma extensão das propostas educacionais da escola, a ansiedade em relação ao desenvolvimento e ao futuro da criança será aplacada por parte da família e a criança se sentirá mais segura e aceita em suas limitações, podendo chegar ao pleno desenvolvimento de suas capacidades.

A família deve ser sempre acolhida pela escola para que a parceria de trabalho possa funcionar e dar bons frutos. Casos em que a criança necessita ser medicada e acompanhada em tratamento clínico devem ser muito bem entendidos pela escola, pois 
a criança que usa medicação pode apresentar sonolência, perda de apetite e mesmo agressividade para se adaptar ao medicamento ou pelo fato de não estar medicada. Devemos nos lembrar sempre que a camada social atendida pelas escolas públicas é a desfavorecida, marginalizada que enfrenta desemprego, desinformação e subempregada. Muitas vezes não retornam às consultas clínicas, não compram o medicamento com regularidade, ou se recusam a medicar a criança porque "ouviram dizer" que o medicamento causa dependência, ou que isso é coisa para "gente doida". Assim, faz parte do trabalho da equipe multiprofissional esclarecer o caso de cada criança com as suas famílias, orientarem quanto às questões clínicas e criarem uma relação de confiança, segurança e reciprocidade com a família para que o trabalho da educação espacial, junto às crianças a educação infantil possa encontrar respaldo, se solidificar e produzir resultados expressivos, no âmbito do conhecimento, das práticas de ensino especial e sociais, para que as crianças e suas famílias possam se sentir pertencentes da comunidade escolar, exercer sua cidadania com autonomia e poder prever um devir melhor para o grupo familiar no âmbito da sociedade.

\section{REFERÊNCIAS BIBLIOGRÁFICAS}

BRASIL. Resolução № 2, Institui Diretrizes Nacionais para a Educação Especial na Educação Básica. Brasília: MEC/CNE, 2001.

BRASIL. Lei 9394 de 20 de Dezembro de 1996. Brasília: Presidência da república, 1996. http://www.planalto.gov.br/ccivil 03/leis/L9394.htm Acessado em 29 de Maio. 2016.

BRASIL. Política Nacional de Educação Especial na Perspectiva da Educação Inclusiva. Brasília: MEC/SEESP 2007. http://portal.mec.gov.br/arquivos/pdf/politicaeducespecial.pdf Acessado em 20 de Abril. 2016.

BRASIL. Marcos Político-Legais da Educação Especial na Perspectiva da Educação Inclusiva. Brasília: MEC/SEESP 2010.

BRAUN, P. A inclusão de alunos com deficiência intelectual no ensino fundamental de uma escola pública federal. Tese de Doutorado. Universidade do Estado do Rio de Janeiro, 2011. 
POKER, Rosimar Bortolini [et al.]. Plano de Desenvolvimento Individual para o Atendimento Educacional Especializado. São Paulo: Cultura Acadêmica; Marília: Oficina Universitária, 2013.

História da $\quad$ Educação Inclusiva no

https://www.portaleducacao.com.br/conteudo/artigos/pedagogia/a-historia-da-educacaoinclusiva-no-brasil/50748

SASSAKI, Romeu. Kazumi. Inclusão: construindo uma sociedade para todos. Rio de janeiro: WVA, 1997.

SILVA. Aline Maria. Educação especial e inclusão escolar: História e fundamento. Curitiba: IBPEX, 2010.

VYGOSTSKY, Lev Semenovich. A formação social da mente. Rio de Janeiro: Martins Fontes, 1996. 